\title{
3D light robotics
}

Glückstad, Jesper; Palima, Darwin; Villangca, Mark Jayson; Bañas, Andrew

\section{Published in:}

Proceedings of SPIE

Link to article, DOI:

$10.1117 / 12.2217404$

Publication date:

2016

Document Version

Publisher's PDF, also known as Version of record

Link back to DTU Orbit

Citation (APA):

Glückstad, J., Palima, D., Villangca, M. J., \& Bañas, A. (2016). 3D light robotics. In B. Gu, H. Helvajian, \& A. Piqué (Eds.), Proceedings of SPIE (Vol. 9738). [97380A] SPIE - International Society for Optical Engineering. Proceedings of SPIE - The International Society for Optical Engineering https://doi.org/10.1117/12.2217404

\section{General rights}

Copyright and moral rights for the publications made accessible in the public portal are retained by the authors and/or other copyright owners and it is a condition of accessing publications that users recognise and abide by the legal requirements associated with these rights.

- Users may download and print one copy of any publication from the public portal for the purpose of private study or research.

- You may not further distribute the material or use it for any profit-making activity or commercial gain

- You may freely distribute the URL identifying the publication in the public portal

If you believe that this document breaches copyright please contact us providing details, and we will remove access to the work immediately and investigate your claim 


\title{
3D Light Robotics
}

\author{
Jesper Glückstad ${ }^{* 0}$, Darwin Palima*, Mark Villangca*, Andrew Banas ${ }^{\circ}$ \\ *DTU Fotonik, Dept. of Photonics Engineering, \\ Technical University of Denmark, Ørsted Plads 343 \\ ${ }^{\circ}$ OptoRobotix ApS, SCION DTU, Diplomvej 381 \\ DK-2800 Kgs. Lyngby, Denmark \\ Email: jesper.gluckstad@fotonik.dtu.dk \\ www.ppo.dk www.GPCphotonics.com www.OptoRobotix.com
}

\begin{abstract}
As celebrated by the Nobel Prize 2014 in Chemistry light-based technologies can now overcome the diffraction barrier for imaging with nanoscopic resolution by so-called super-resolution microscopy ${ }^{1}$. However, interactive investigations coupled with advanced imaging modalties at these small scale domains gradually demand the development of a new generation of disruptive tools, not only for passively observing at nanoscopic scales, but also for actively reaching into and effectively handling constituents in this size domain. This intriguing mindset has recently led to the emergence of a novel research discipline that could potentially be able to offer the full packet needed for true "active nanoscopy" by use of so-called light-driven micro-robotics or Light Robotics in short.
\end{abstract}

Keywords: light-driven micro-robotics, light-matter interaction, nanobiophotonics, optical micro-manipulation

\section{INTRODUCTION}

In an early 2011 outline in a Nature Photonics " ${ }^{2}$ "news \& views" and further in an invited review paper in Laser \& Photonics Reviews ${ }^{3}$ we promoted the idea of fabricating a new class of socalled topology optimised dielectric microstructures and pioneering their use in so-called lightdriven micro-robotics or just Light Robotics. The aim in this new and disruptive undertaking took its original point of departure in our 2005-published Optics Express ${ }^{4}$ paper where rather preliminary, flat silica structures were lithographically fabricated and subsequently 3D lasermanipulated with six-degrees-of-freedom using multiple coin-like optical handles. Light Robotics is aiming to mature this original mindset by seeking new means of uniquely combining and jointly optimising light-based 3D micro-fabrication and 3D light-based micro-manipulation to harness a so-called structure-mediated micro-to-nano coupling paradigm for optimised lightmatter interaction at the smallest scales. Today it is possible to 3D-print advanced threedimensional structures using two-photon micro-fabrication with features down to a few tens of

Laser 3D Manufacturing III, edited by Bo Gu, Henry Helvajian, Alberto Piqué, Proc. of SPIE Vol. 9738, 97380A · C 2016 SPIE · CCC code: 0277-786X/16/\$18 · doi: 10.1117/12.2217404 
nanometers. Moreover, optical micro-manipulation is routinely applied these days for simultaneously trapping and manipulating a plurality of tiny objects in real-time and throughout a full 3D-space. The carefully optimised merger of these scientific achievements is hence a natural next step and is in fact gradually starting to set the stage for new research endeavours using advanced drone-like steering of optimally shaped tools for Light Robotics at the cellular level and in full 3D.

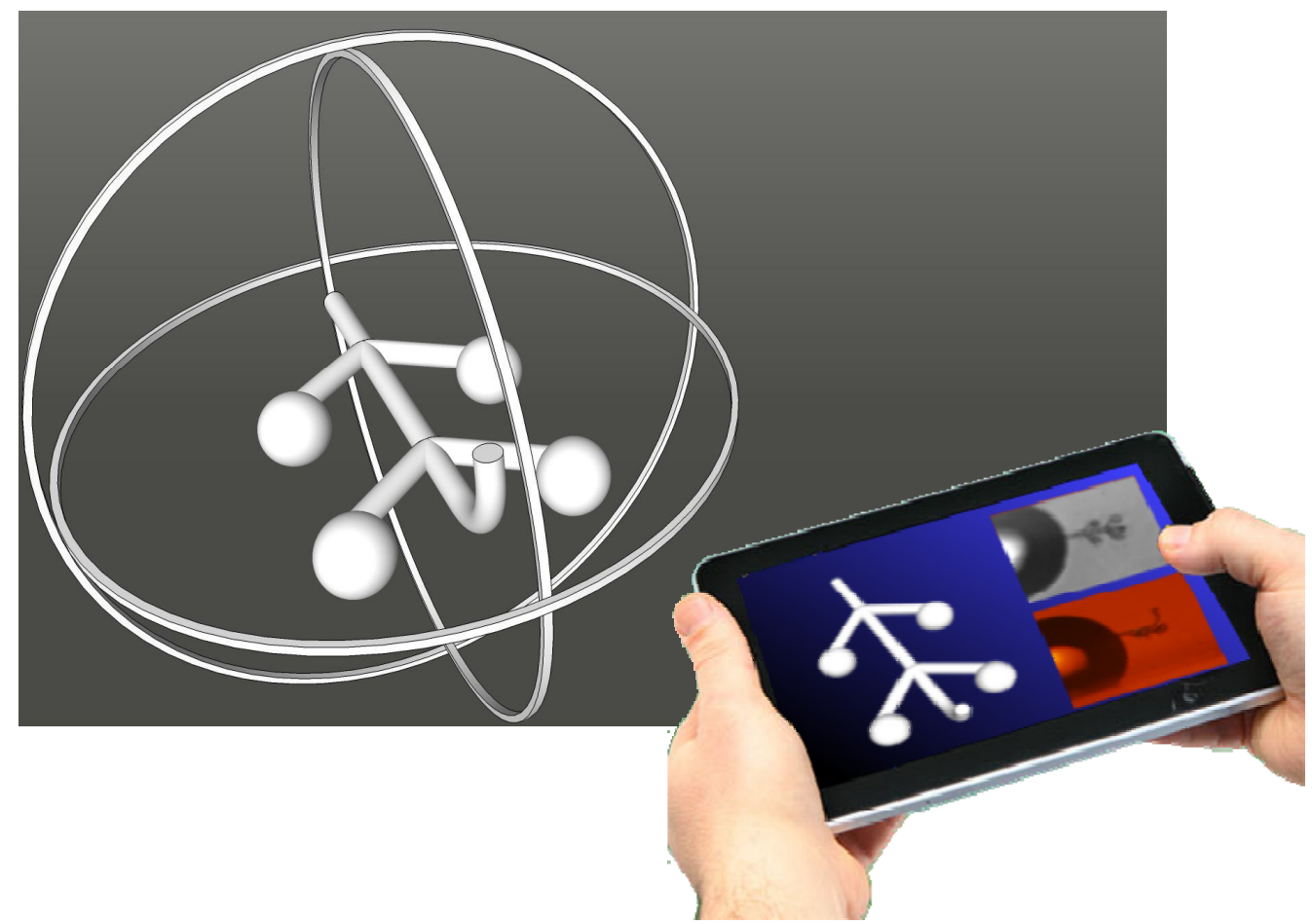

Fig. 1: Example of real-time steering a "light robot" with a nano-tip in full 3D like a drone.

\section{TOWARD LIGHT-DRIVEN MICRO-ROBOTICS}

Taking direct inspiration from the highly successful concept of $\mathrm{AFM}^{5}$ (Atomic Force Microscopy) coupled with the scientific desire to break out of 2D-constrained scanning and enter a full 3D mode of operation and being operable in a biologically friendly environment, one can envision a multifunctional 'lab-on-a-tip' approach operated like a remote-control micro-drone. By applying contemporary 3D-printing such as two-photon micro-fabrication, such multifunctional micro-vessels equipped with e.g. nano-biophotonic tip-tools or taperings can now be sculpted and monolithically fabricated as part of a larger micron-sized platform amenable to 3D optical micro-manipulation as conceptualised in Fig. 1. This way, the overall platform serves 
as an advanced coupling device from the far field generated micron-scaled manipulation beams to nanometer scaled tip-tools providing an effective means of pin-pointing nano-tip locations without the need for nanoscopic resolving capabilities and instead inferring exact 3D-positions based on easily observed and tracked micron-sized platforms.
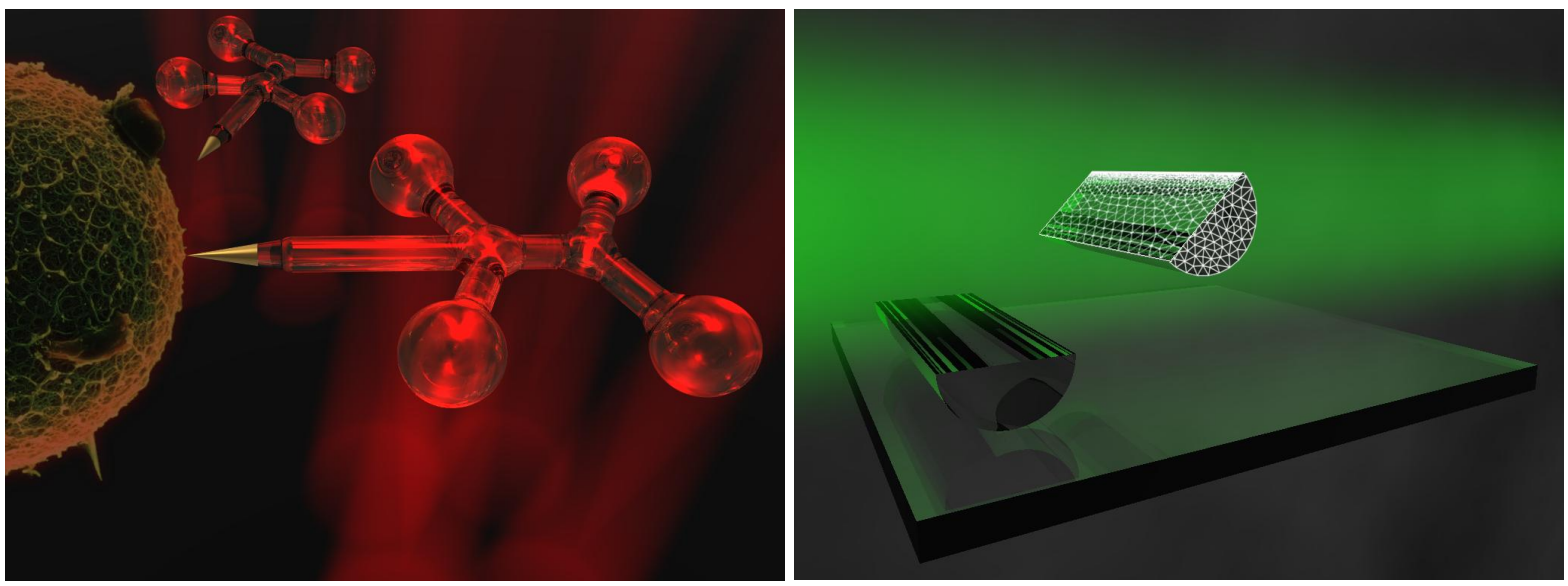

Fig. 2: Micro-to-nano coupling paradigm (left) and topology optimization of a "light foil" (right)

In the aforementioned 2005-paper ${ }^{4}$ we first proposed and demonstrated real-time, optical actuation of micro-fabricated micron-sized robotic tools using planar silica microstructures with coin-like handles fabricated through micro-lithographic techniques and steered by real-time dynamic beams coupled through far field optics with a large field of view ${ }^{6-9}$. This was an effective precursor for full 3D-operated Light Robotics using 3D-printed micro-structures with and nano-featured tools. As envisioned in Fig. 2 (left), one can picture a plurality of functionalized light robotic tools for delivering space- and/or time-programmed cellular stimuli even using bioactive chemicals that otherwise cannot co-exist in solution. A light robotic tool can in principle target receptors on cell membranes and even exploit their signalling network to initiate biochemical processes within the interior of a biological cell. Without advanced chemical functionalization such tools can still be used to deliver programmed mechanical stimuli for probing the molecular origin of so-called cellular mechano-transduction - a mechanism that is known to convert mechanical signals on cell membranes to biochemical responses inside the cell. Hence, one can in principle extend this structure-mediated micro-to-nano coupling such that the 3D light-printed structures not only serve to relay mechanical motion and forces, but also directly couples light and matter at sub-diffraction scales. The optimisation and "sculpting" of both light 
and matter and their interaction can be pursued in a plurality of ways like e.g. obtaining the strongest thrust on a so-called optical lift ${ }^{10}$ or to achieve the most efficient propelling of a lightdriven micro-machine or whatever design is aimed for. Hence, there will be an exciting new avenue for Light Robotics engineering along this path by applying advanced volume-oriented computational tricks from so-called topology optimization. As sketched in figure 2 (right) a first step for this undertaking could be to define external boundaries of the desired design (e.g. a socalled "light foil") followed by computer-based optimizations in a step-by-step manner that gradually converges to an optimised object shaping given particular boundary conditions.

\section{WAVE-GUIDED OPTICAL WAVEGUIDES APPLIED IN LIGHT ROBOTICS}

A few years ago, we took a first small step into this exciting new direction by our so-called "Wave-guided Optical Waveguides" or WOWs featured on the cover of Optics Express ${ }^{11}$ and subsequently used in an OSA-published flyer highlighting Optics in 2013 hot topics. These WOWs can uniquely act as free-standing and joystick-controlled waveguides that captures, couples and concentrates another independent far-field light to a sub-diffraction limited tipexcitation that can be used in difficult geometries ${ }^{12,13}$ as a sort of "nano-torch".

(a)

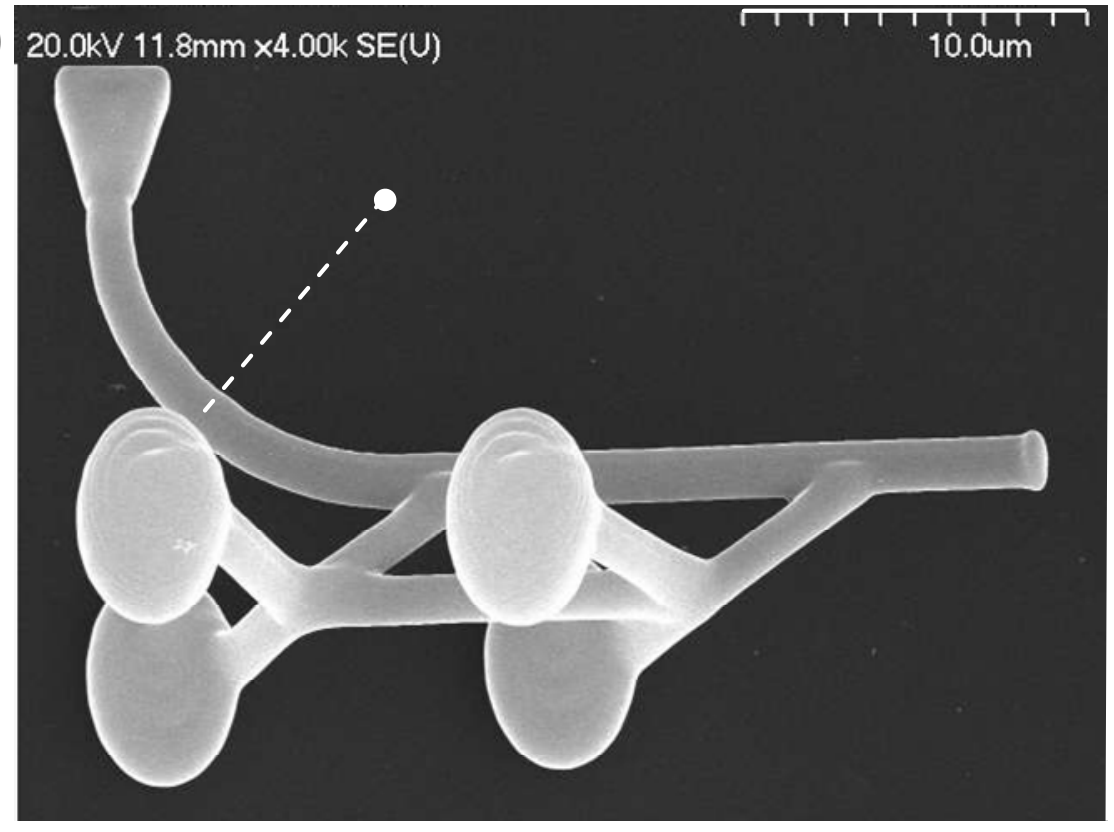

(b)

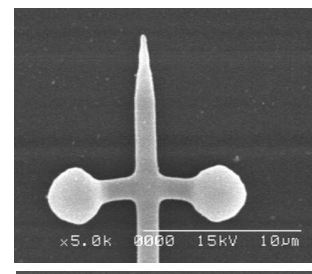

(c)

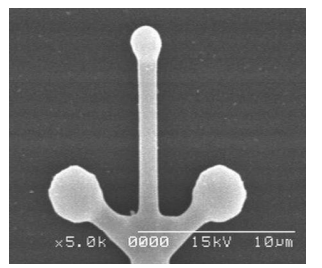

(d)

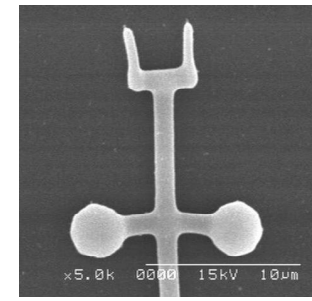

Fig. 3: SEM-images adapted from ref. [11] showing our so-called Wave-guided Optical Wavguides (WOWs) that are fabricated, steered and even capable of waveguiding light. 
A plurality of disruptive scientific applications can be pursued ranging from new nanobiophotonics undertakings in cellular environments to completely new and advanced optogenetics $^{14}$ modalities not supported with known technology. In particular, by way of biomimetic motivation, one aim could be for designing light-driven tools imitating the ubiquitous mosquito or even the first light-driven robotic "virus" (i.e. below fig 4) to enable light-triggered material transport to and from intra- and intercellular configurations using structure-embedded nanotubes ${ }^{15}$. Such applications are a direct, though highly ambitious, extension of our previously pioneered and proprietary WOWs. A so-called Super-WOW (a next generation WOW) could also be functionalized and equipped with a metal- or a light-guiding polymer nanowire for delivering a tiny cargo like remote DNA by means of photo-chemically un-caging in a highly controlled way utilizing the WOW light-guiding mechanisms at selected wavelengths.

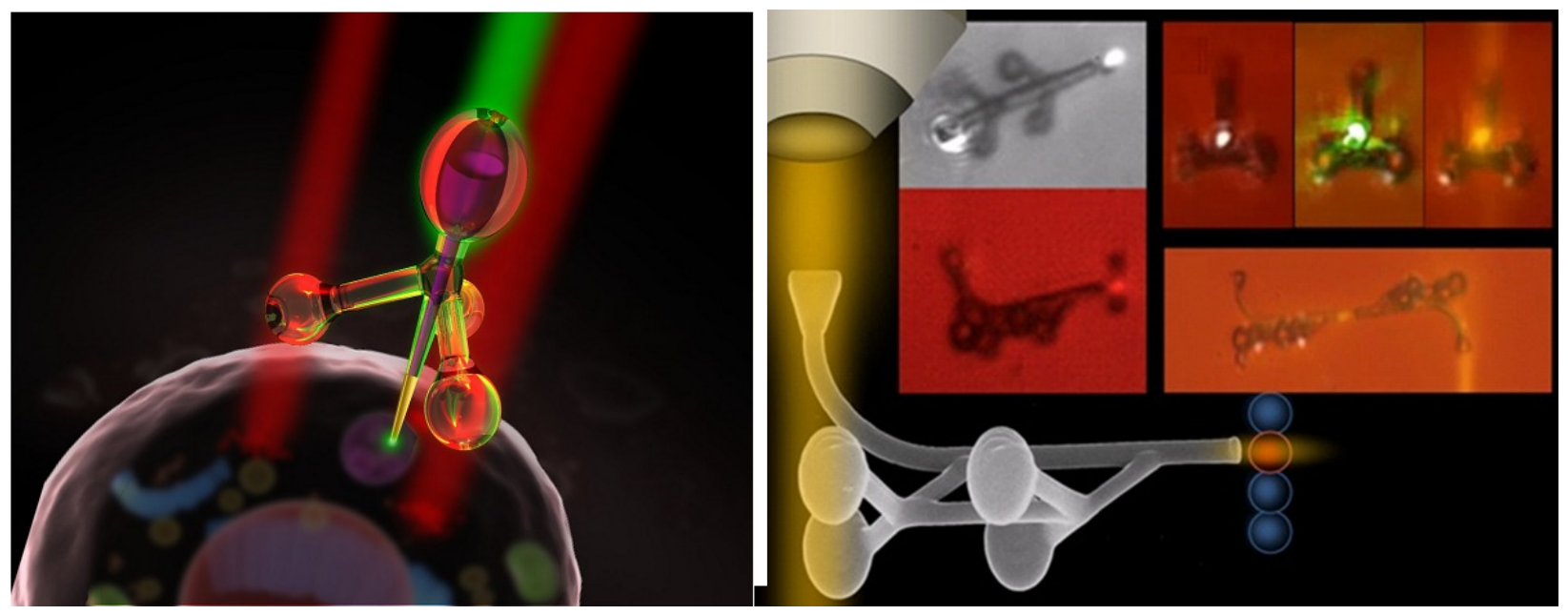

Fig. 4 (Left) Anticipated "Super-WOW" acting as light-driven "virus" on a cell membrane. (Right) Composite figure showing actual proof-of-principle experiments with the first generation of Wave-guided Optical Waveguides.

Thereby, a user has effectively obtained a unique and "wireless" nano-injector with 6-DOF control in full 3D for precise intracellular gene delivery to e.g. the nucleus of a single cell. The combined use of spatially shaped contemporary light sources such as supercontinuum light sources with Super-WOWs opens for even more intriguing scientific applications where different wavelengths can be orchestrated simultaneously ${ }^{16,17}$ to facilitate a gentle transfection via a very precise photoporation process and a subsequent quantitative photochemical control. Moreover, photoactivated enzymatic patternings that offer full spatio-temporal control over the presentation 
of bioactive proteins to direct cells in 3D culture, can be possibly carried-out using future SuperWOWs.
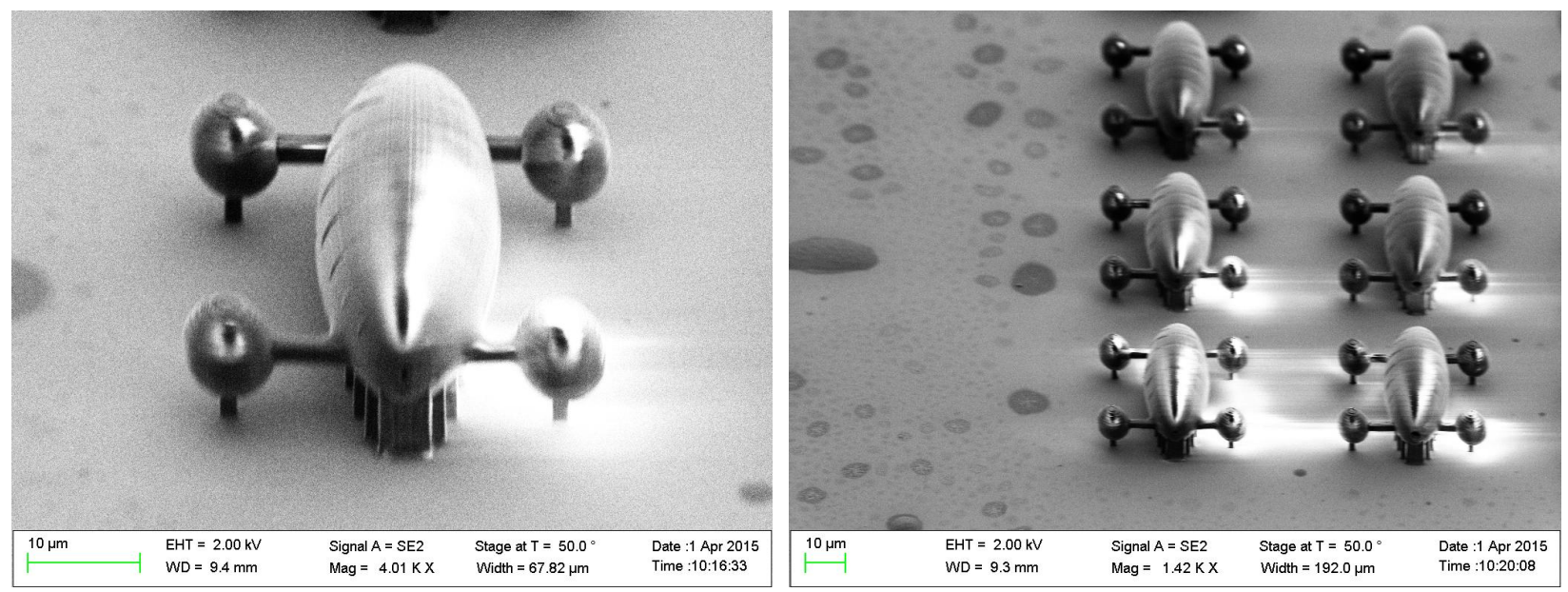

Fig. 5: Initial test 3D-prints of non-optimized hollow micro-body structures for potential cargodelivering Light Robotics.

\section{CONCLUSIONS AND OUTLOOK}

Concretely, we are utilizing the Nanoscribe-facility located at DTU Danchip for 2PP-based 3Dprinting of topology optimised structures. Until recently we relied on external international collaborators to fabricate these structures based on our proprietary designs and 3D-renderings. By gathering all the theoretical, computational, fabricational and experimental knowhow at one place will allow us to elevate Light Robotics to a completely new level and hopefully getting it fully recognized as a new and independent scientific area on the borderline between a plurality of fundamental and contemporary nano-, bio- and photonics disciplines. As most scientists will acknowledge, it can take a significant time and effort to establish a new scientific area and make it set roots internationally. The two first author's recent invitation to edit a book volume on structure-mediated nano-biophotonics (to be published late 2016 / early 2017), and our recent invitation to deliver a prestigious Plenary Talk at the world renowned IEEE NANO 2016 on the topic of Light Robotics can hopefully help step-by-step to create an increasing awareness of this new, exciting and emerging research field on an international scale. 


\section{REFERENCES}

1. Hell, S.W. “Far-Field, Optical Nanoscopy,” Science 316, 1153 - 1158 (2007).

2. Glückstad, J., "Sculpting the object," Nature Photonics 5, 7-8 (2011).

3. Palima, D., and Glückstad, J., "Gearing for optical micro-robotics: synthetic microstructures actuated by optical trapping and optical manipulation," Lasers \& Photonics Reviews 17, 478494 (2013).

4. Rodrigo, P. J., Gammelgaard, L., Bøggild, P., Perch-Nielsen, I. R., and Glückstad, J. "Actuation of microfabricated tools using multiple GPC-based counterpropagating-beam traps," Opt. Express 13, 6899-6904 (2005).

5. Muller D.J., Dufrene Y.F. "Atomic force microscopy as a multifunctional molecular toolbox in nanobiotechnology," Nature Nanotechnology 3, 261-269 (2008).

6. Ulriksen, H.U., Thøgersen, J., Keiding, S., P.-Nielsen, I., Dam, J., Palima, D. Z., Stapelfeldt, H. and Glückstad, J., "Independent trapping, manipulation and characterization by an alloptical biophotonics workstation," J. Europ. Opt. Soc. Rap. Public. 3, 08034 (2008).

7. Glückstad, J., "Sorting particles with light," Nature Materials 3, 9 - 10 (2004).

8. Rodrigo, P. J., Kelemen, L., Palima, D., Alonzo, C. A., Ormos, P. and Glückstad, J. “Optical microassembly platform for constructing reconfigurable microenvironments for biomedical studies," Opt. Express 17, 6578-6583 (2009).

9. Tauro, S., Bañas, A., Palima, D. and Glückstad, J., "Dynamic axial stabilization of counterpropagating beam-traps with feedback control," Opt. Express 18, 18217-18222 (2010).

10. Swartzlander, G. A. et al., "Stable Optical Lift," Nature Photonics 5, 48-51 (2011).

11. Palima, D., Bañas, A., Vizsnyiczai, G., Kelemen, L., Ormos, P., and Glückstad, J., "Waveguided Optical Waveguides," Opt. Express 20, 2004-2014 (2012).

12. Wu, C.W, Palima, D, Novitsky, A; Ding, W; Gao, D; Shukovsky, S; and Glückstad, J. "Engineering light-matter interaction for emerging optical manipulation applications," Nanophotonics 3, 181-201 (2014).

13. Villangca, M., Casey, D., Glückstad, J., "Optically-controlled platforms for single- and subcellular transfection and surgery," Biophysical Reviews 7, 379-390 (2015). 
14. Papagiakoumou, E., Anselmi, F., Begue, A., Sars, V., Glückstad, J., Isacoff, E., Emiliani, V., "Scanless two-photon excitation of Channelrhodopsin," Nature Methods 7, 848-854 (2010).

15. Yan, R., Gargas, D. and Yang, P., "Nanowire photonics," Nature Photonics 3, 569 - 576 (2009).

16. Villangca, M., Bañas, A., Palima, D., and Glückstad, J. "Dynamic diffraction-limited lightcoupling of 3D-maneuvered wave-guided optical waveguides," Opt. Express 22, 17880-17889 (2014)

17. Villangca, M., Bañas, A., Palima, D., Glückstad, J. "Generalized phase contrast-enhanced diffractive coupling to light-driven microtools," Opt. Eng. 54 (11), 111308 (2015). 